\title{
HEATING AND VENTILATION
}

\section{BRITISH OCCUPATIONAL HYGIENE SOCIETY CONFERENCE}

$\mathrm{T}$ HE eleventh conference of the British Occupational Hygiene Society was held at the Institution of Mechanical Engineers on November 5, the president, Mr. W. H. Walton, occupying the chair. Dr. T. Bedford opened the proceedings with a paper entitled "Requirements for Satisfactory Heating and Ventilation", in which he discussed the suppression of body odour, the combating of airborme infection, the release of toxic materials in factories and the maintenance of comfort. The definition of comfort zones is effected, to a first approximation, by the dry-bulb temperature of the air. This, however, could be mis. leading if radiation, atmospheric humidity and air movement are sufficiently large. These were taken account of by the speaker's "corrected effective temperature", though it had to be remembered that individual preference differed, and so, too, did the general attitudes in different seasons and countries. To be pleasant as well as comfortable the surrounding atmosphere had to contribute an element of stimulation. This was associated in the first place with air-movement, which, while perceptible, was insufficient to constitute a draught. The upper desirable limit depended on temperature. Very low or very high relative humidities were often objectionable, but the optimum was not sharply defined. The method of supplying artificial heat was important in the avoidance of stuffiness. Warm walls had been found satisfactory, while the lower part of the body should be warmer than the upper with a gradient of $2^{\circ} \mathrm{F}$. to $3^{\circ} \mathrm{F}$. over the height of a standing man. Heated ceilings required cautious use, for this reason. Experiments with heated floors suggested that discomfort began when the surface exceeded $77^{\circ} \mathrm{F}$.

The engineering approach to air conditioning was explained by Mr. B. G. Lawrence, of the National College for Heating, Ventilating, Refrigeration and Fan Engineering. His paper, which will be of the utmost value to consultants in heating and ventilation, explained in detail the basic methods of heating, cooling and humidifying air and drew comparisons from which it was possible to decide upon the system best suited to a particular application.

Work in hot environments was dealt with by Dr. A. R. Lind, of the Medical Research Council Unit, for Research in Climate and Working Efficiency. In hot surroundings men rapidly experience discomfort and fatigue; their working capacity falls, errors of perception and judgment appear and, ultimately, serious physiological disturbances are followed by collapse. The heat exchange between the body and its surroundings is complicated by a rise in body temperature during work which becomes greater in climates that are too hot. An appraisal of the heat stress imposed by given surroundings necessitates an understanding of the way in which the heat exchange will be influenced by the thermoregulatory system of the human body. In the absence of such regulation a man hard at work would increase in temperature by $14.4^{\circ} \mathrm{F}$. an hour. In hot surroundings, acclimatization after about two weeks plays an important part in enabling regulation to be extended beyond the normal limit; it is associated with improved circulation, which helps the transfer of heat from deep tissues to the surface of the skin. Dr. Lind compared various indexes of heat stress and concluded that the predictive value of the sweat-rate system was valid under the widest range of conditions. It was of practical value to be able to use an index to define the upper limit of a tolerable thermal environment. Work was at present in hand, for example, to determine the safe duration of exposure for personnel engaged in mine-rescue operations. Permissible limits for everyday work were important in industrial, mining and Service activities ; a comparison of naval and mining proposals was made. The final section of the paper dealt with measures which could be taken to relieve heat stress and the probable physiological response to them.

Flight Lieut. J. Billingham (Institute of Aviation Medicine) and Mr. D. J. Day (Royal Aircraft Establishment) discussed cabin air-conditioning in military aircraft, the former covering physiological aspects and the latter engineering. The problem of keeping the pilot comfortable presented novel features. The air-cooling system had to extract a considerable amount of heat so that the difference in temperature between inlet and exit air might be as high as $50^{\circ} \mathrm{F}$., even with a very high rate of air change. The difference between wall and air temperature might also be large and in either direction. Heat was produced by electronic equipment, but the exposed cabin walls were cold; on the other hand, the development of supersonic aircraft would result in heating of the cabin skin, and solar radiation had the same effect on its upper parts. The humidity of air taken in to ventilate high-flying aircraft was practically zero. Water could be added in civil machines, but the need to save weight might not permit this in military craft. The clothing of air-crews varied a great deal. Impermeable pressure suits might suffer from condensation of body moisture upon the inner surfaces and, for this reason alone, all such suits should be ventilated. The pilot had to be able to control the air temperature to some extent, depending on his mean radiant temperature and his clothes. The degree of variation, and of comfort provided, was a matter of balance between his deterioration in mental performance and the increase in the performance of the aircraft resulting from saving of weight. A more severe stress could be imposed on a man embarking on a short sortie than would be tolerated during a long expedition.

Mr. Day directed attention to the properties of the I.C.A.N. standard atmosphere, which was the raw material for calculations on air supplies. Real conditions often departed from this ideal specification. In aircraft powered by gas turbines, a bleed from the compressor pressurized the cabin. This air required to be cooled ; its volume was decided by the heat load and the leakage rate. Enemy action had to be considered in military planes and an excess of $4 \mathrm{lb}$./in. ${ }^{2}$ was not exceeded. Up to $9 \mathrm{lb}$./in. ${ }^{2}$ was acceptable in civil machines, giving a cabin altitude of $8,000 \mathrm{ft}$. at a true height of $47,000 \mathrm{ft}$. Under the skin of the cabin, thermal insulation was provided by up to $1 \mathrm{in}$. of superfine fibreglass. Uniformity of 
temperature was achieved by careful arrangement of the air inlets. About $15 \mathrm{lb} . / \mathrm{min}$. was a typical figure for the air supply to a single-seat cockpit. Primary air cooling was performed by an air-to-air ramoperated exchanger. The heat picked up could not be rejected into the air stream, so it had to be used up by evaporating water or by heating up the considerable amount of fuel carried, which might even be refrigerated before loading. The final cooling, before admission to the cabin, was obtained by expansion. Temperature control was by a mixing valve.

The conference was concluded with a paper by Surgeon Commander S. Miles, of the Royal Naval Physiological Laboratory, who said that the nuelear propulsion unit brought with it the possibility that a man might in future spend a full commission beneath the surface of the sea, not necessarily as part of a defence programme, since the cargo-carrying submersible vessel was now the subject of study. The problem to be faced was the confinement of a crew in complete isolation while they worked, played, ate and slept encompassed by the sea. During this time a high standard of health and morale had to be maintained. The cumulative effect of a discharge of toxic agent made the risks abnormal. Carbon monoxide, carbon dioxide, body odours, fumes from cooking, paint, machinery and batteries had to be dealt with. The provision of oxygen from storage cylinders or chemical sources was expensive in space and might be replaced by the electrolysis of sea water or the absorption of dissolved gas, following the plan adopted by fishes. Water was readily obtained by distillation, but food was a problem. Cyclic feeding had been mooted by space-ship planners. The screening of the reactors was efficient and the only source of radiation could be an escape of coolant, which was guarded against by continuous monitoring. Luminous watch and instrument dials were banned. As a voyage progressed there was a swing to classical music in the popular taste, while conversation tended to become deeper. Educational courses were popular and afforded compensation for the Iong immurement. Exercise remained a difficulty.

The papers presented at this conference and the discussion on them will be printed in Vol. 2, part 3, of the Annals of Occupational Hygiene.

C. N. Davies

\title{
SELECTIVE OXIDATION OF TETRAPYRROLE SIDE.CHAINS
}

\author{
By J. BARRETT and P. CLEZY \\ Institute of Medical Research, Royal North Shore Hospital of Sydney
}

$I_{c}^{N}$

$\mathrm{N}$ studies to determine the nature of the sidechains and their relative positions on the nucleus in the tetrapyrroles, porphyrin $a$ (ref. 1) and chlorin $a_{2}$ (ref. 2), we have made considerable use of selective oxidation methods, some of which are new to this field while others have been further investigated. Since these methods have also been of value in preparing various model compounds they are of general application in this field and this communication summarizes our experience.

Because of evidence that porphyrin $a$ and chlorin $a_{2}$ (ref. 3) are hydroxylated compounds a method was required which would oxidize the alcohol group to carbonyl and thus demonstrate whether it was conjugated to the ring, but which would not cleave the vinyl or extended vinyl side-chain, known to be present in these tetrapyrroles. Fischer ${ }^{4}$ employed potassium dichromate in pyridine to achieve this type of oxidation, but this oxidant in our hands gave poor yields together with degradation products. When acetone or glacial acetic acid was used as solvent, products with oxyporphyrin type spectra rapidly formed. However, oxidation of both primary and secondary hydroxyl groups could be readily effected with the reagent developed by Jones et al. ${ }^{5}$ for the oxidation of acetylenic carbinols, in which chromium trioxide/sulphuric acid is used in conjunction with acetone as solvent. Oxidation was too rapid to allow for the appearance, with the dihydroxy porphyrins, of compounds with a single oxidized hydroxyl group. The order of reactivity in the porphyrin series of compounds was $-\mathrm{CH}_{2} \mathrm{OH}>-\mathrm{CHOHCH}_{3}$ $>>>-$ CHO. Thus mono- and di-hydroxymethyl, or hydroxyethyl, deuteroporphyrins were converted to the corresponding formyl or acetyl porphyrins in high yield. 2-formyl 4-hydroxyethyl could be oxidized to 2-formyl 4-acetyl-deuteroporphyrin, little of the carboxy compound being formed. Where oxida- tion of the formyl group was preferentially required, the hydroxyl groups could be protected by acetylation. In this way 2-formyl 4-hydroxyethyl-deuteroporphyrin was converted to 2-carboxy 4-hydroxyethyl-deuteroporphyrin and 2-hydroxymethyl 4 formyl-deuteroporphyrin to 2-hydroxymethyl 4-carboxy-deuteroporphyrin. The formyl groups could be completely protected by formation of a Girard complex, but usually this device was not required.

In the dihydroporphyrin series (chlorins, rhodins) rhodin $g_{7}$ alcohol (derived from rhodin $g_{7}$ by reduction of the 3 formyl group with $\mathrm{NaBH}_{4}$ ) was smoothly oxidized by this technique to the formyl compound, though care was required to avoid over-oxidation as the dihydroporphyrin ring tends to break down more readily than the porphyrin nucleus. The presence of side reactions was more marked in the case of the 2- $\alpha$-hydroxyethyl compounds derived from phæophorbide $a$, pyrophæophorbide $a$, rhodochlorin and pyrochlorin ${ }^{3}$, where a second compound with an oxyporphyrin type spectrum and a low Willstätterhydrochloric acid number was obtained. The appearance of this type of degradation product on oxidation of the chlorin 2-hydroxyethyl compounds and its absence from the 3-hydroxymethyl compound are probably related to the significantly slower rate of oxidation of the secondary alcohol.

The procedure for oxidation was as follows. A few $\mathrm{mgm}$. of the tetrapyrrole in $5 \mathrm{ml}$. of acetone, freshly distilled over potassium permanganate, cooled to $0^{\circ} \mathrm{C}$., was treated under a nitrogen atmosphere with a very small drop of the chromium trioxide reagent which had previously been flushed with nitrogen. The drop was applied to the side of the test-tube and washed down by the acetone. The spectrum of the compound rapidly changed to that of the acid form and the formation of the oxidized product could be followed with a hand spectroscope. 